\title{
The end-of-the year 2020 issue: on disasters and challenges, research and the power of love
}

\author{
Giorgina Barbara Piccoli ${ }^{1,2}$
}

Published online: 26 November 2020

(C) Italian Society of Nephrology 2020

\section{The visionary is the only true realist}

\section{Federico Fellini.}

When the year 2020 began some of us made jokes based on the fact that, in Italian, the word "venti" means both winds and twenty. "It will be a stormy year" they said.

It was indeed.

Closing this final issue of 2020 was an occasion to reflect upon how our lives have changed, and to do so from the peculiar perspective of our journal.

This end-of-the year issue gathers a series of interesting reviews, elicited on the occasion of the 60th Congress of the Italian Society of Nephrology; these span from diabetic nephrology, to onconephrology, dialysis, and transplantation (https://doi.org/10.1007/s40620-020-00922-x, https://doi. org/10.1007/s40620-020-00724-1, https://doi.org/10.1007/ s40620-020-00820-2, https://doi.org/10.1007/s40620-02000793-2, https://doi.org/10.1007/s40620-020-00787-0, https://doi.org/10.1007/s40620-020-00750-z, https://doi. org/10.1007/s40620-020-00726-z). The series is commented upon by De Nicola in a lively editorial that starts with a quote from the great filmmaker Federico Fellini: "I was led by hand to choose a job that is the only one to me, the only one that allows me achieving myself in the most joyful, most immediate, form" (https://doi.org/10.1007/s40620-02000856-4) and, indeed, the editorial, submitted between the two waves of COVID-19 underlines the importance of being a nephrologist and being proud of it.

This reinvestment and sense of belonging can also be read as one of the reasons for the striking increase in submissions that challenged several editors of scientific journals in this difficult year. Journal of Nephrology will end this year with over 1300, if not over 1400 submissions, a

\footnotetext{
Giorgina Barbara Piccoli

gbpiccoli@yahoo.it

University of Torino, Torino, Italy

2 Nephrologie, Centre Hospitalier Le Mans, Le Mans, France
}

considerable increase over the approximately 800 submissions we received last year. Only a minority are papers on various aspects of COVID-19, and most of them regard our core profession. Similar increases have been observed in other Nephrology or Internal Medicine journals. A cynical view holds that physicians probably had more time to dedicate to writing during the various phases of lockdown since they were less distracted by travelling, congresses, and, overall life; however, sharing the optimistic visionary outlook Fellini calls realism, I was impressed by the high quality of the submitted papers. They are not just old articles pulled out of the bottom drawer. They are often elegant, innovative, and well done.

Furthermore, since the first phase of the crisis, I was struck by the deep involvement of many colleagues that, while fighting all day on the front lines against the pandemic, kept on answering, reviewing, editing, often late at night. Please, accept my deepest thanks and admiration.

It is a pleasure to be able to contribute to the discussion on the COVID-19 challenges in our journal. Nothing is simple; health care workers are not only perceived as heroes; they may be stigmatized, as Uvais reports (https:// doi.org/10.1007/s40620-020-00833-x). New solutions are needed, and the importance of rediscovering home dialysis is recalled by Scarpioni and Michel (https://doi.org/10.1007/ s40620-020-00822-0), while Coppo and Trimarchi comment on an interesting case in which Mahajan and colleagues report the results of treatment with Eculizumab in a paediatric patient with COVID-19 (https://doi.org/10.1007/s4062 0-020-00725-0 and https://doi.org/10.1007/s40620-02000858-2). Meanwhile, a teaching case by Doevelaar reports on an unsual complication, the recurrence of nephrotic syndrome, presumably induced by SARS-CoV-2, thus broadening the already wide spectrum of kidney lesions induced by the virus (https://doi.org/10.1007/s40620-020-00855 -5). Indeed, as the review by Faruk, Fiaccadori and Cravedi recalls, there is much that we do not know, and something that we think to know today will probably not be confirmed tomorrow (https://doi.org/10.1007/s40620-020-00789-y). 
Life goes on, and in this issue three original papers discuss dialysis-related topics: Nochaiwong reports on the importance of albumin levels in the transition to peritoneal dialysis in a large cohort of over 1100 patients from Thailand (https://doi.org/10.1007/s40620-020-00716-1); Loutradis reports on the new approaches to the establishment of dry weight on hemodialysis, a never-ending quest for clinical nephrologists, in an elegant randomised controlled trial (https://doi.org/10.1007/s40620-020-00745-w), while, again on the topic of home dialysis, the advantages of remote monitoring in peritoneal dialysis are described by Milan Manani and colleagues (https://doi.org/10.1007/ s40620-020-00812-2).

In clinical nephrology, we chose a series of papers regarding different aspects of IgA nephropathy for this issue, starting from a review on the differences between children and adults (Coppo https://doi.org/10.1007/s40620-020-00859 -1), continuing with the somehow deceiving results of the dual blockade of the renin-angiotensin system, from the STOP-IgA trial (Lennartz, https://doi.org/10.1007/s4062 0-020-00836-8), then on to the potential benefits of more aggressive treatment in advanced CKD stages (Sun, https:// doi.org/10.1007/s40620-020-00752-x), to the involvement of different pathways (Zhang, https://doi.org/10.1007/s4062 0-020-00722-3) and finally to the long-term renal survival in a large series of more than 1200 children from China (Xia).

Obstetric nephrology is enriched by a position statement on contraception in chronic kidney diseases, in which Attini coordinates the Italian project group on kidney and pregnancy (https://doi.org/10.1007/s40620-020-00717-0), adding to the four previous position statements and best practices, and Ferreira recalls the risks of pregnancy-related AKI (https://doi.org/10.1007/s40620-020-00711-6).

A special place has been reserved in this issue to clinical and ethical issues in kidney transplantation. Two original papers discuss complementary aspects of the complex relationship between immunodepression and cancer: Tessari analyses the risk of death in older recipients in a competitive risk analysis (https://doi.org/10.1007/s40620-02000847-5), while Eccher summarizes a systematic review on donor-transmitted cancer in kidney transplant recipients, a fearful event that is not always easy to detect, as also exemplified by a teaching case proposed by the same team (https ://doi.org/10.1007/s40620-020-00775-4 and https://doi. org/10.1007/s40620-020-00778-1). The papers are further commented upon in an editorial by our Australian friends, from a medical point of view and from the patient's perspective (Coates, Horton, https://doi.org/10.1007/s40620-02000802-4 and https://doi.org/10.1007/s40620-020-00807-z).

A hot ethical topic, regarding contact between the deceased donor's family and the recipients is extensively discussed by De Santo and a team of co-workers (De santo, https://doi.org/10.1007/s40620-020-00902-1). The paper is commented by an exceptional editorial, written by Reg Green, father of Nicholas Green, a boy who died following a robbery attempt in Italy, and whose family, by donating the organs to seven Italian patients, and by supporting organ donation and transplantation in this country, showed that the miracle of transforming hate into love is still possible.

There is no better way to end the Christmas issue of this terrible year than with the words of Reg Green.

"All organ donors save lives. But they do something more: they elevate life. The story of our son, Nicholas, is one example among hundreds of thousands

When we were planning our vacation to Italy, we played a game. In it, Nicholas was a Roman soldier returning after years of service on the frontiers-the Scottish border, Gaul, the Alps, all places where he'd seen evidence of the Roman Empire. Back in Rome you'll be treated like a hero, we told him. People will write poems about you, you'll be given gold medals, children will cheer when your name is mentioned.

It was just a game, but it all came true. With this difference: that Nicholas conquered, like all organ donors conquer, not by the force of arms, but by the power of love-and that, of course, is much stronger."

Reg Green 